\title{
PHYTOCHEMICAL AND FREE RADICAL SCAVENGING ACTIVITY OF HENNA LEAVES EXTRACTS
}

Hassan, R. A.*; H. B. Hamed*; A. F. Hamail ${ }^{\star \star}$ and M. A. El-Hendawy ${ }^{\star \star *}$

* Agri. Chemistry Dept., Faculty of Agricultural, Mansoura University, Egypt.

** Vegetable Dept., Faculty of Agricultural, Damietta University, Egypt.

*** Agri. Chemistry Dept., Faculty of Agricultural, Damietta University, Egypt.

\begin{abstract}
The ability of Lawsonia inermis (Henna) to prevent the initiation of free radicals that cause cellular damage was investigated in vitro. The plant leaves were extracted using methanol (ME) and diethylether (EE) and the active ingredient, Lawsone (2hydroxy 1,4-naphthaquinone) was separated by column chromatography. In the reducing power assay, the more antioxidant compounds convert the oxidation form of iron $\left(\mathrm{Fe}^{+3}\right)$ in ferric to ferrous chloride $\left(\mathrm{Fe}^{+2}\right)$. The reducing power capacity of the methanol and etheric extracts were significantly less than that of vitamin $\mathrm{C}$. Total phenolic (TPC) and total flavonoid contents (TFC) were evaluated. In this study, etheric extract has the highest TPC and TFC. Radical scavenging activities of lawsone and the extracts were tested against $\mathrm{DPPH}, \mathrm{NO} \mathrm{O}^{\circ}, \mathrm{SOD}$ and $\mathrm{HO}^{\circ}$. The strongest free radical inhibition was demonstrated by etheric extract against radical scavengers, DPPH and SOD in a dose-dependent on $\mathrm{IC}_{50}$ value of 18.17 and 137 $\mu \mathrm{g} / \mathrm{mL}$, respectively. Also, the activity of lawsone to scavenge nitric oxide radical was higher than that of the standard (quercetin) and (ME, EE) extracts. These results clearly indicate the useful effect of lawsone and these extracts as antioxidants and anticancer agents.
\end{abstract}

Keywords: Lawsonia inermis, Free radicals, Antioxidant, Lawsone, Radical scavengers.

\section{INTRODUCTION}

Free radicals are created when cells use oxygen to generate energy. These by-products are generally reactive oxygen species (ROS) such as superoxide anion, hydroxyl radical and hydrogen peroxide that result from the cellular redox process.

At low or moderate concentrations, ROS exert beneficial effects on cellular responses and immune function but at high levels, free radicals and oxidants generate oxidative stress, a deleterious process that can damage cell structures, including lipids, proteins, and DNA (Pham-Huy et al., 2008). Oxidative stress plays a major part in the development of chronic and degenerative ailments such as cancer, autoimmune disorders, rheumatoid arthritis, cataract, aging, cardiovascular and neurodegenerative diseases, (Willcox et al., 2004 and Pham-Huy et al., 2008). The human body has several mechanisms to immune oxidative stress by producing antioxidants, which are either naturally produced in situ, or externally supplied through foods and/or supplements. These antioxidants act as free radical scavengers 
Hassan, R. A. et al.

by preventing and repairing damages caused by ROS, and therefore can enhance the immune defense and lower the risk of cancer and degenerative diseases (Pham-Huy et al., 2008). In recent years, there is an increasing interest in finding antioxidant phytochemicals, because they can inhibit the propagation of free radical reactions, protect the human body from diseases (Terao and Piskula, 1997). The most effective components seem to be flavonoids and phenolic compounds of many plant raw materials, are found particularly in herbs, seeds, and fruits. Their metal-chelating capabilities and radical- scavenging properties have enabled phenolic compounds to be as effective free radical scavengers and inhibitors of lipid peroxidation (Terao and Piskula, 1997).

Henna (Lawsonia inermis Linn.) invites attention of the researchers worldwide for its important pharmacological activities as anti-inflammatory and anticancer agents. Lawsonia inermis Linn. (Family: Lythraceae) is a much branched glabrous shrub or small tree (2-6 m in height), cultivated for its leaves although stem bark, roots, flowers and seeds have also been used in traditional medicine. This plant is a worldwide known as a cosmetic agent used to stain hair, skin and nails (Hanna et al., 1998). The plant is reported to contain 14 active components i.e Lawsone, Esculetin, Fraxetin, Isoplumbagin, Scopoletin, Betulin, Betulinic acid, Hennadiol, Lupeol, Lacoumarin, Laxanthone, Flavone glycosides and two pentacytic triterpenes. It has analgesic, hypoglycemic, hepatoprotective, immunostimulant, antiinflammatory, antibacterial, wound healing, antimicrobial, antifungal, antiviral, antiparasitic, antitrypanosomal, antidermatophytic, antioxidant, antifertility, tuberculostatic and anticancer properties, (Chaudhary et al., 2010)

The present study on henna leaf extracts and its active constituent, lawsone was carried out to evaluate the phytochemical and antioxidant effect.

\section{MATERIALS AND METHODS}

\section{Collection of Plant And Authentication}

The leaves of Lawsonia inermis were collected from gardens of New Damietta in August 2012 and the plant materials were authenticated by Prof. M. Serag, Department of Botany, Faculty of Science, Damietta University.

\section{Extraction}

\section{Methanolic Extract (ME)}

Powder of dried henna leaves $(40 \mathrm{~g})$ were mixed with methanol $(1.0 \mathrm{~L})$ in a closed flask and kept for $24 \mathrm{hrs}$. Shaking frequently during the first 6 hours and allowed to stand for 18 hours. Thereafter, it was filtered rapidly taking precautions against the loss of the solvent. The methanolic extract was concentrated to dryness in a rotary evaporator under reduced pressure and controlled temperature $\left(40-50{ }^{\circ} \mathrm{C}\right)$. The extract was stored in a refrigerator at $4{ }^{\circ} \mathrm{C}$ till further use.

\section{Etheric Extract (EE)}

The etheric extract method according to (Berger and Sicker, 2009) has been followed with some modifications. Powder of dried henna leaves (40 g) 
were placed in a large beaker and distilled water $(2.0 \mathrm{~L})$ were added. The suspension was stirred using a magnetic stirrer with heating while the temperature is kept at $70{ }^{\circ} \mathrm{C}$. After $45 \mathrm{~min}$, the colour of the green suspension turns to brown. After $4 \mathrm{~h}$, solid $\mathrm{NaHCO}_{3}(8.4 \mathrm{~g})$ is added. The suspension is filtered by gravity overnight over three large glass funnels with filter paper (diameter $30 \mathrm{~cm}$ ). The filtrates are combined and acidified to $\mathrm{pH} 3.0$ using $0.12 \mathrm{M} \mathrm{HCl}$ and extracted with diethyl ether $(4 \times 200 \mathrm{~mL})$. The combined ethereal phases were washed with water $(3 \times 50 \mathrm{~mL})$ and dried over anhydrous $\mathrm{Na}_{2} \mathrm{SO}_{4}$, then concentrated to dryness in a rotary evaporator and gave a crude, $0.6 \mathrm{~g}$, which kept in a refrigerator at $4{ }^{\circ} \mathrm{C}$ till further use.

Separation of Lawsone (L)

The above crude lawsone was purified by column chromatography. The yield of pure lawsone was $10 \%$ of the crude which checked by TLC (0.06 g, m.p. $191-193{ }^{\circ} \mathrm{C}$ ) and had similar IR spectroscopy typical to that of the authentic commercial sample of 2-hydroxy-1,4-naphthaquinone which purchased from Sigma-Aldrich company, Germany.

\section{Phytochemical Screening}

Terpenes, tannins, flavonoids, saponins, resins and alkaloids were detected in methanolic extract according to the method described by Harborne (1998).

\section{Determination of Total Phenolic Content}

Total polyphenols were determined using the Folin-Ciocalteu method according to (Li et al., 2007). The absorbance was measured at $750 \mathrm{~nm}$. using gallic acid $(10-200 \mathrm{mg} / \mathrm{mL})$, a standard curve was obtained with linearity. Total phenol contents were expressed as milligram gallic acid equivalent $(\mathrm{GAE}) / \mathrm{g}$ extract.

\section{Determination of Total Flavonoids Content}

Aluminum chloride colorimetric method was used for the determination of total flavonoids as described in the method of Chang et al., 2002, using quercitin as standard. The calibration curve was prepared using quercetin solutions of $2.5,10,15,20,25$ and $30 \mu \mathrm{g} / \mathrm{mL}$ concentrations in methanol. The flavonoids content was determined from the standard curve and the results were expressed as $\mathrm{mg}$ of quercetin equivalents $(\mathrm{QE}) / \mathrm{g}$ extract.

\section{HPLC For Polyphenols of Plant Leaves Extract}

Phenolic compounds were extracted according to the method outlined by Ben-Hammouda et al. (1995).

Identification of individual phenolic compound was performed on a Hewlett-Packard HPLC (Model 1100), using a hypersil C18 reversed phase column $(250 \times 4.6 \mathrm{~mm})$ with $5 \mu \mathrm{l}$ particle size. Injection by means of a Rheodyne injection valve (Model 7125) with $50 \mu \mathrm{m}$ fixed loop was used. A constant flow rate of $1.0 \mathrm{ml} / \mathrm{min}$ was used with two mobile phases (A) $0.5 \%$ acetic acid in distilled water at pH 2.6 and (B) $0.5 \%$ acetic acid in $99.5 \%$ acetonitrile. The elution gradient was linear starting with $(A)$ and ending with (B) over 35 minutes, using an UV detector set at wavelength $254 \mathrm{~nm}$. Phenolic compounds of each sample were identified by comparing their relative retention times with those of the standards mixture chromatogram. Ten standard phenolic compounds were used namely pyrogallol, gallic acid, 
Hassan, R. A. et al.

protocatechuic, catechin, catechol, vanillic acid, salicylic acid, o-coumaric acid, ellagic acid and cinnamic acid, which were obtained from sigma (St. Louis, USA) and Merck-Schuchardt (Munich, Germany) Chemical Companies.

\section{Nitric Oxide Radical Scavenging Activity}

The nitric oxide radical scavenging capacity of the plant leaf constituents was measured by Griess reaction (Sangameswaran et al., 2009). Quercitin was used as reference standard and was treated in the same way as that of the sample. Sodium nitroprusside in phosphate buffer saline (PBS) was used as control. The nitric oxide radical scavenging activity of extracts, lawsone and quercitin was calculated according to the following equation:

$\%$ Nitric oxide radicals scavenging $=\left[\left(A_{o}-A_{1}\right) / A_{o}\right] \times 100$

$A_{o}$ : Absorbance of sodium nitroprusside in PBS (without sample or Quercitin).

$A_{1}$ : Absorbance in the presence of the sample or quercitin.

\section{Scavenging of Hydroxyl Radical}

The hydroxyl radicals $\left(\mathrm{HO}^{\circ}\right)$ in aqueous media were generated through the Fenton system. The hydroxyl radical bleached the safranin, so decreased the absorbance of the reaction mixture indicating a decrease in hydroxyl radical scavenging ability (Winterbourn and Sutton, 1984). The absorbance was measured at $520 \mathrm{~nm}$. The suppression ratio for $\mathrm{HO}^{\circ}$ radical was calculated from the following expression:

$\%$ Hydroxyl Radical Scavenging $=\left[\left(A_{i}-A_{0}\right) /\left(A_{c}-A_{0}\right)\right] \times 100$

$A_{i}$ : Absorbance in the presence of the tested compound.

$A_{0}$ : Absorbance in the absence of the tested compound.

$A_{c}$ : Absorbance in the absence of the tested compound, EDTA-Fe(II) and $\mathrm{H}_{2} \mathrm{O}_{2}$

\section{Estimation of Reducing Power}

Reducing power assay was determined according to the method of (Ferreira et al., 2007). Absorbance was measured at $700 \mathrm{~nm}$ against the corresponding blank solution.

\section{DPPH (2, 2 -diphenyl-1-picryl-hydrazyl) Free Radical Scavenging Activity \\ DPPH radical scavenging capacity was determined according to the} technique reported by (Martins et al., 2008). Sample solution was diluted with DMSO and in each reaction mixture, the solution was mixed with $2.0 \mathrm{~mL}$ of $100 \mu \mathrm{M}$ DPPH. The mixture was shaken vigorously and allowed to reach a steady state at room temperature for $30 \mathrm{~min}$. in dark. Decolorization of DPPH was determined by measuring the absorbance at $517 \mathrm{~nm}$.

$\%$ Scavenging Activity $=\left(A_{0}-A_{1} / A_{0}\right) \times 100$

$A_{0}$ : Absorbance without extract.

$A_{1}$ : is the absorbance in the presence of the extract or standard sample. Superoxide Dismutase Activity Assay

Superoxide dismutase activity was determined by the method of (Dechatelet et al., 1974). The inhibition percent was calculated from the following equation: 
$\%$ Inhibition of reduction for nitro blue dye $=[($ Rate of absorbance change of blank - Rate of absorbance change of extracts) / Rate of absorbance change of blank)] $\times 100$.

\section{RESULTS AND DISCUSSION}

\section{Phytochemical Screening of Henna}

The preliminary phytochemical screening reveals the presence of terpenes, tannins, flavonoids, resins and alkaloids, however saponins is not found in the sample. The results were shown in Table 1.

Table 1. Qualitative analysis of phytochemical constituents of henna leaves

\begin{tabular}{|l|c|}
\hline \multicolumn{1}{|c|}{ Constituent } & Level $^{*}$ \\
\hline Terpenes & ++ \\
Tannin & ++ \\
Flavanoid & ++ \\
Saponins & + \\
Resins & + \\
Alkaloids & ++ \\
\hline \multirow{2}{*}{$+=$ Low concentration, ++ = High concentration, $-=$ Not detectable. }
\end{tabular}

\section{Quantitative Estimations}

Two different solvent extracts were used in this study i.e methanol and diethylether.

The total polyphenols contents (TPC) in henna leaves ranged from 71.16 in methanolic extract to $150.83 \mathrm{mg} \mathrm{GAE} / \mathrm{g}$ in etheric extract. Phenols and polyphenolic compounds, such as flavonoids, are widely found in food products derived from plant sources, and they have been shown to possess significant antioxidant activities (Nagavani et al., 2010). Total flavonoids content (TFC) of the extracts were also determined using aluminum chloride assay. The total flavonoids content (TFC) varied from 32.91 in methanolic extract to $67.42 \mathrm{mg} \mathrm{QE} / \mathrm{g}$ in etheric extract. The etheric extract has the highest amounts of TFC (67.42 mg QE/g extract), while the lowest amount (32.91 QE/g extract) was observed in methanolic extract. In this study, etheric extract has the highest TPC and TFC, that can be further tested for its ability to inhibit different free radicals. Total phenolic and flavonoid contents for henna leaves extracts are collected in Table 2.

Table 2. Total phenolic and flavonoid contents for henna leaf extracts

\begin{tabular}{|l|c|c|}
\hline \multicolumn{1}{|c|}{ Extracts } & $\begin{array}{c}\text { Total Polyphenols } \\
(\mathbf{m g ~ G A E} / \mathbf{g})^{\mathbf{a}}\end{array}$ & $\begin{array}{c}\text { Total Flavonoids } \\
\left.\text { ( }^{\mathbf{m g ~ Q E}} / \mathbf{g}\right)^{\mathbf{b}}\end{array}$ \\
\hline Methanolic & 71.16 & 32.91 \\
\hline Etheric & 150.83 & 67.42 \\
\hline
\end{tabular}

${ }^{a}(\mathrm{mg}$ GAE/g): $\mathrm{mg}$ of gallic acid equivalent per $\mathrm{g}$ of dry plant extract.

${ }^{b}(\mathrm{mg} \mathrm{QE} / \mathrm{g})$ : $\mathrm{mg}$ of quercetin equivalent per $\mathrm{g}$ of dry plant extract. 
Hassan, R. A. et al.

\section{HPLC For Polyphenols Extracted From Plant Leaves}

Figure 1, shows HPLC chromatogram with different retention times and peak area for main components found in henna leaves. Comparing results with standard compounds, it could be noticed that catechol was the predominant identified compounds with a percentage value of $8.05 \%$ as shown in Table 3. Other nine components could be detected and collected in Table 3, which are ellagic acid, salicylic acid, protocatechuic acid, vanillic acid, catechin, gallic acid, o-coumaric acid, pyrogallol and cinnamic acid. The chromatogram also shows a highest area \% percent of 13.0 for unknown compounds.

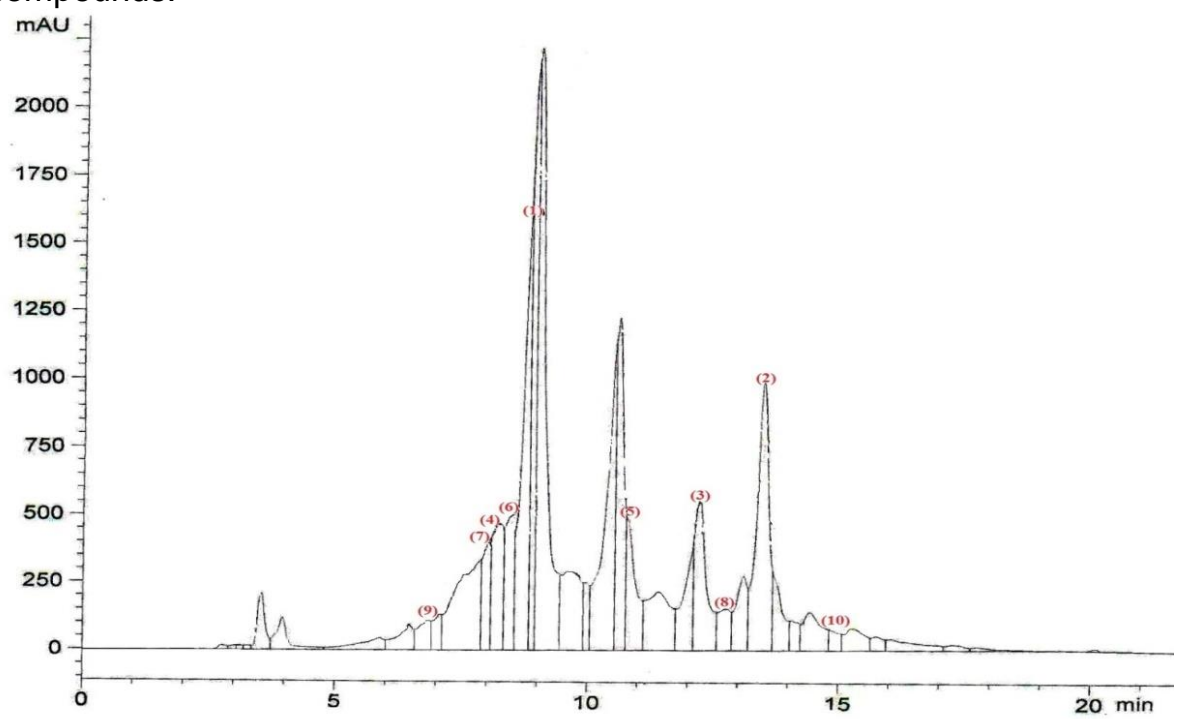

Fig. 1. HPLC chromatogram of Lawsonia inermis leaves. (1) Catechol, (2) Ellagic acid, (3) Salicylic acid, (4) Protocatechuic acid, (5) Vanillic acid, (6) Catechin, (7) Gallic acid, (8) o-Coumaric acid, (9) Pyrogallol and (10) Cinnamic acid.

Table 3. Retention time (Rt) and area \% for polyphenol components in henna leaves separated by HPLC

\begin{tabular}{|l|l|c|c|}
\hline No. & \multicolumn{1}{|c|}{ Components } & Rt & Area \% \\
\hline 1 & Catechol & 8.823 & 8.047 \\
\hline 2 & Ellagic acid & 13.489 & 8.039 \\
\hline 3 & Salicylic acid & 12.224 & 4.484 \\
\hline 4 & Protocatechuic acid & 8.203 & 3.384 \\
\hline 5 & Vanillic acid & 10.760 & 3.081 \\
\hline 6 & Catechin & 8.464 & 3.034 \\
\hline 7 & Gallic acid & 8.067 & 2.056 \\
\hline 8 & o-coumaric acid & 12.754 & 1.270 \\
\hline 9 & Pyrogallol & 6.827 & 0.908 \\
\hline 10 & Cinnamic acid & 14.807 & 0.516 \\
\hline 11 & Unknown & 8.980 & 13.00 \\
\hline
\end{tabular}




\section{Antioxidant Activity}

The antioxidant reactions involve multiple steps including the initiation, propagation, branching and termination of free radicals. The antioxidants which inhibit the formation of free radicals from their unstable precursors are called preventive antioxidants, and those which interrupt the radical chain reaction (propagation and branching) are the 'chain-breaking' antioxidants (Ou et al., 2001).

\section{DPPH Assay}

DPPH method is widely used to test the ability of compounds as free radical scavengers or hydrogen donors and to evaluate the antioxidative activity of plant extracts (Martins et al., 2008). From Fig.2 it is clear that DPPH has maximum absorption at $517 \mathrm{~nm}$ and the antioxidant reduces it to the yellow coloured diphenyl-picrylhydrazine. The concentration of antioxidant needed to decrease the initial DPPH concentration by $50 \%\left(\mathrm{IC}_{50}\right)$ is a parameter widely used to measure the antioxidant activity. A lower $\mathrm{IC}_{50}$ value indicates a higher antioxidant power. The etheric extract has the strongest inhibition (58.7\%) against DPPH radical using $25 \mu \mathrm{g} / \mathrm{mL}$ while methanolic extract gave ibhibition value of $(51.3 \%)$ at the same concentration.

Figure 3. shows the inhibition percentage of the radical scavenger DPPH for different concentrations $(10-25 \mu \mathrm{g} / \mathrm{ml})$ of the EE and ME compared to the standard vitamin $\mathrm{C}(\mathrm{Vc})$. Based on the $\mathrm{IC}_{50}$ values, the ability of the extracts and standard to scavenge the DPPH free radical can be given in the following order:

Vc $(10.1 \mu \mathrm{g} / \mathrm{mL})>\operatorname{EE}(18.17 \mu \mathrm{g} / \mathrm{mL})>\mathrm{ME}(23.9 \mu \mathrm{g} / \mathrm{mL})$.

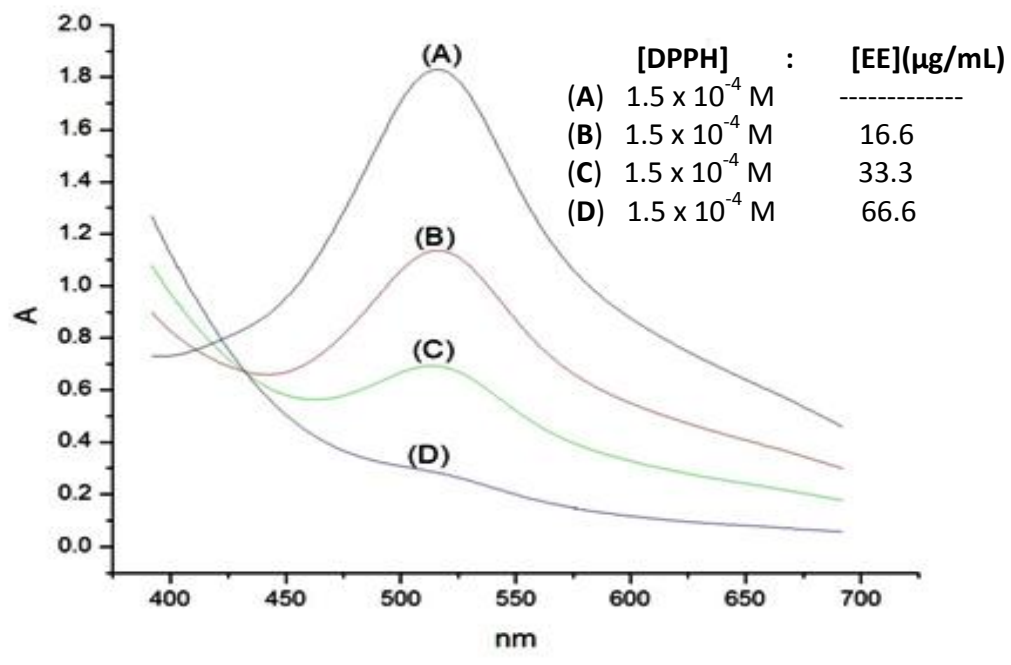

Fig.2. Effect of etheric extract (EE) concentration on the UV-visible spectra of DPPH in DMSO solvent at $25^{\circ} \mathrm{C}$. 
Hassan, R. A. et al.

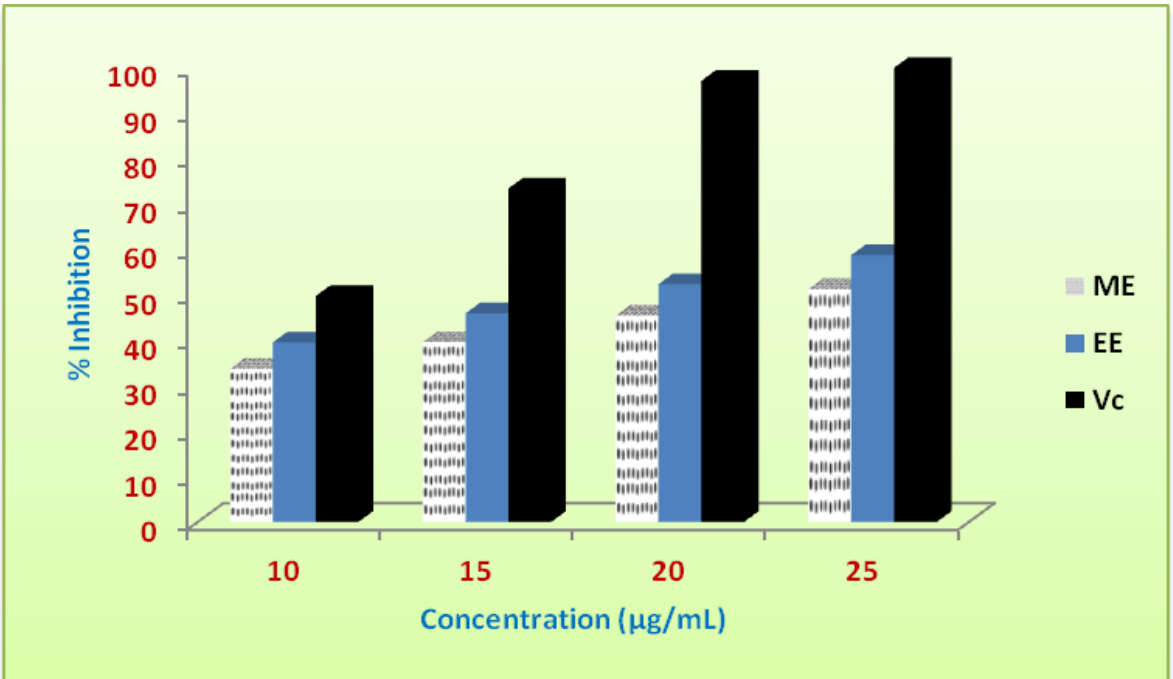

Fig. 3. Effect of different concentrations for EE, ME and Vc on \% inhibition of DPPH.

\section{Scavenging of Nitric Oxide Radical}

Nitric oxide, generated from sodium nitroprusside in aqueous solution at the physiological $\mathrm{pH}$ (7.4), interacts with oxygen to produce nitrite ions, which is measured by Griess reaction (Sangameswaran et al., 2009). In addition to reactive oxygen species, nitric oxide is also implicated in inflammation, cancer and other pathological conditions (Nabavi et al., 2008). In this study, Lawsone and extracts (EE, ME) were added to compete with oxygen leading to produce nitric oxide. Figure 4 summarizes the effect of different concentrations of lawsone, EE, ME extracts and the standard quercetin on the \% inhibition of nitric oxide radical scavenger. The \% inhibition was increased with increasing concentration of the lawsone and extracts. The etheric extract has shown to be a better reducing power than that of both metanolic extract and the standard (Quercetin). However, activity of lawsone was higher than that of standard and extracts. 


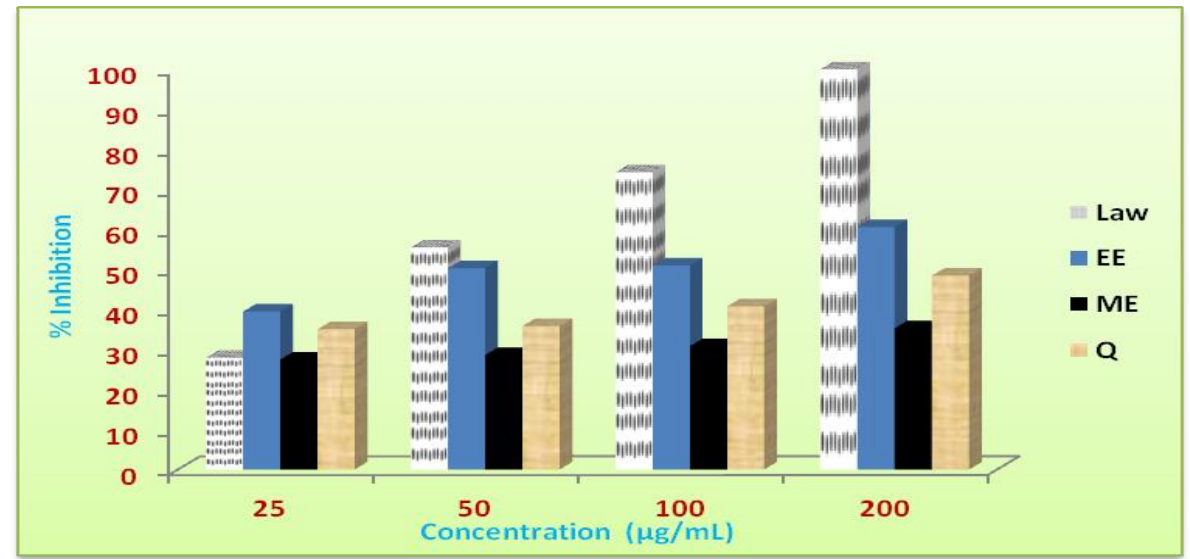

Fig. 4. Nitric oxide scavenging activity of lawsone, ME and EE of Lawsonia inermis using quercitin $(Q)$ as reference standard

\section{Superoxide Dismutase Activity Assay}

Superoxide anion plays an important role in plant tissues and is involved in the formation of other cell-damaging free radicals (Duan et al., 2007). Superoxide anions are generated in vitro by the phenazine methosulphate/NADH system and monitored by the reduction of nitroblue tetrazolium. Figure 5 shows the effects of scavenging superoxide anions by the $\mathrm{EE}$ and $\mathrm{ME}$ extracts. Maximum superoxide anion inhibition (Figure 5) was shown by EE $(72.0 \%)$ and then ME $(56.9 \%)$ at the concentration $200 \mu \mathrm{g} / \mathrm{ml}$. It has been reported that, the increasing order in the superoxide anion scavenging activity was due to presence of hydroxyl group of the phenolics which may contributes to its superoxide anion scavenging activity by their electron donation (Bravo, 1998). Similarly, in this study EE extract might scavenge the superoxide anion in a similar way since they are rich in phenolics containing more hydroxyl groups.

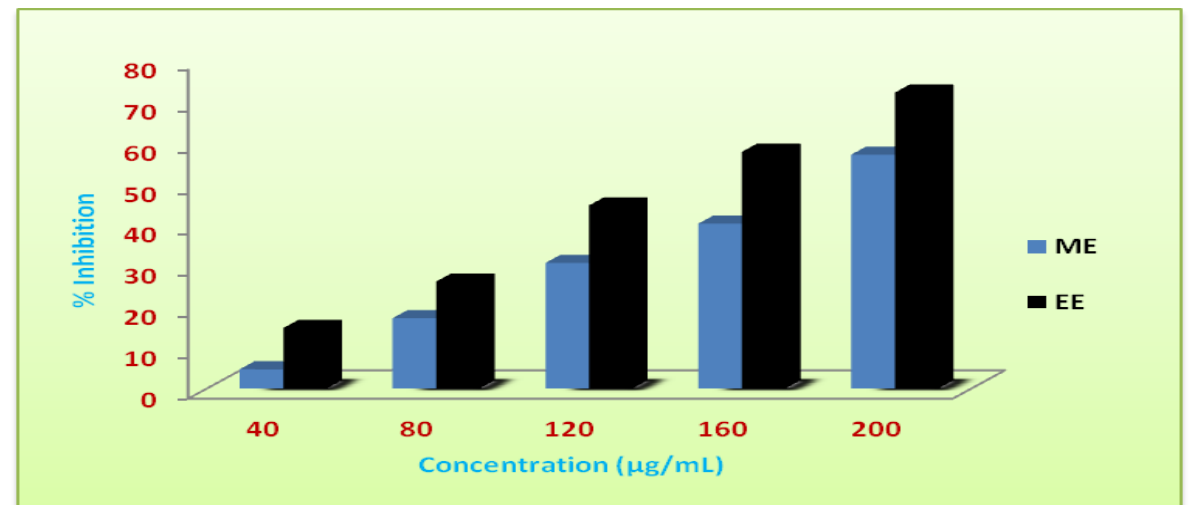

Fig. 5. Superoxide anion scavenging activity of different concentration of ME and EE extracts of Lawsonia inermis leaves.

Scavenging of Hydroxyl Radical 
Hassan, R. A. et al.

The hydroxyl radicals $\left(\mathrm{HO}^{\circ}\right)$ in aqueous media were generated through the Fenton system $\left(\mathrm{Fe}^{++} / \mathrm{EDTA} / \mathrm{H}_{2} \mathrm{O}_{2}\right)$. The hydroxyl radical bleached the safranin, so decreased the absorbance of the reaction mixture indicating a decrease in hydroxyl radical scavenging ability (Winterbourn and Sutton, 1984).

In the site-specific reactions, methanolic extract at concentrations from 160 to $480 \mu \mathrm{g} / \mathrm{mL}$, inhibited the production of hydroxyl radicals by $10.0-75$ $\%$ (Fig. 6). Further more, methanolic extract was high in their total polyphenol and total flavonoid contents. Phenols act as antioxidants and scavenge the hydroxyl radical generated from the Fenton reagent. Attempts to use lawsone and etheric extracts as scavengers of hydroxyl radical under the same conditions were unsuccessful.

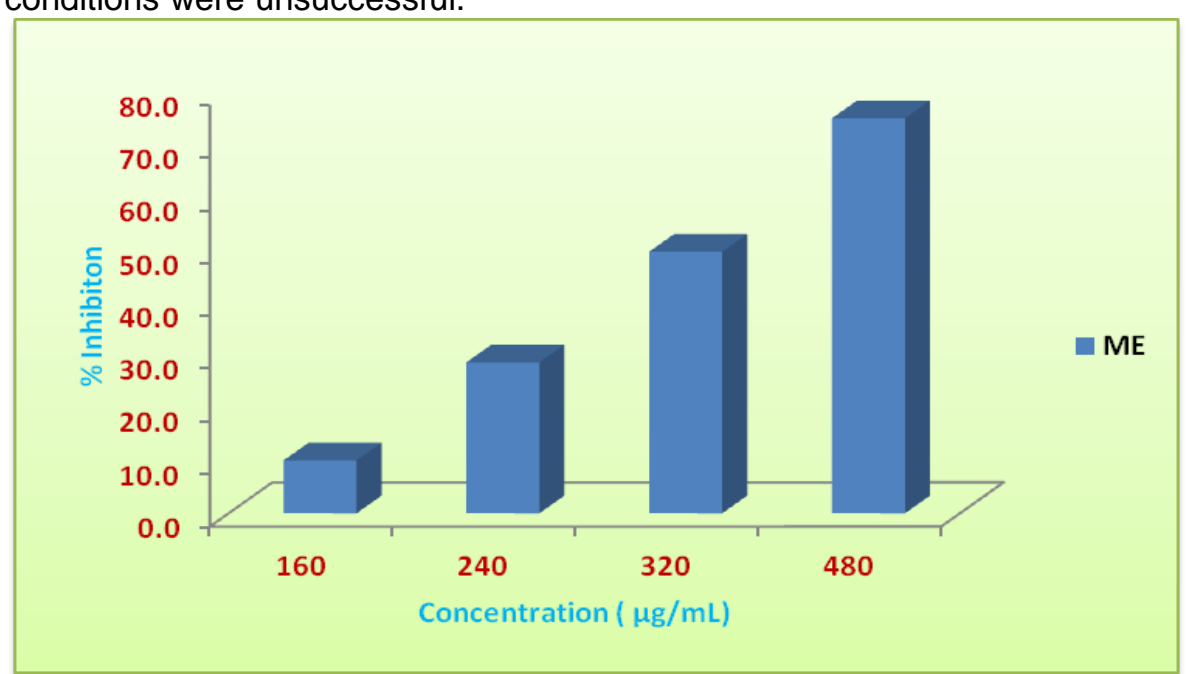

Fig. 6. Hydroxyl radical scavenging activity of different concentration of methanolic extract (ME).

\section{Reducing Power Assay}

The more antioxidant compounds convert the oxidation form of iron $\left(\mathrm{Fe}^{+3}\right)$ in ferric to ferrous chloride $\left(\mathrm{Fe}^{+2}\right)$. In this assay, the henna extracts were able to convert the oxidized form of $\mathrm{Fe}^{3+}$ into the reduced form $\mathrm{Fe}^{2+}$ (Fig. 7). The reducing power capacity of the methanol and etheric extracts, with absorbance value of $(0.411)$ and $(0.614)$, respectively were significantly less than that of vitamin $C(2.418)$ at $25 \mathrm{\mu g} \mathrm{mL}^{-1}$. The reducing properties are generally associated with the presence of reductones. The antioxidant action of reductones is based on the breaking of the free radical chain by donating a hydrogen atom (Gordon,1990). The result indicated that the marked reducing power of the henna extracts seems to be due to presence of polyphenols which may act in a similar effect as reductones by donating the electrons and reacting with free radicals to convert them into more stable products and terminate free radical chain reaction. 


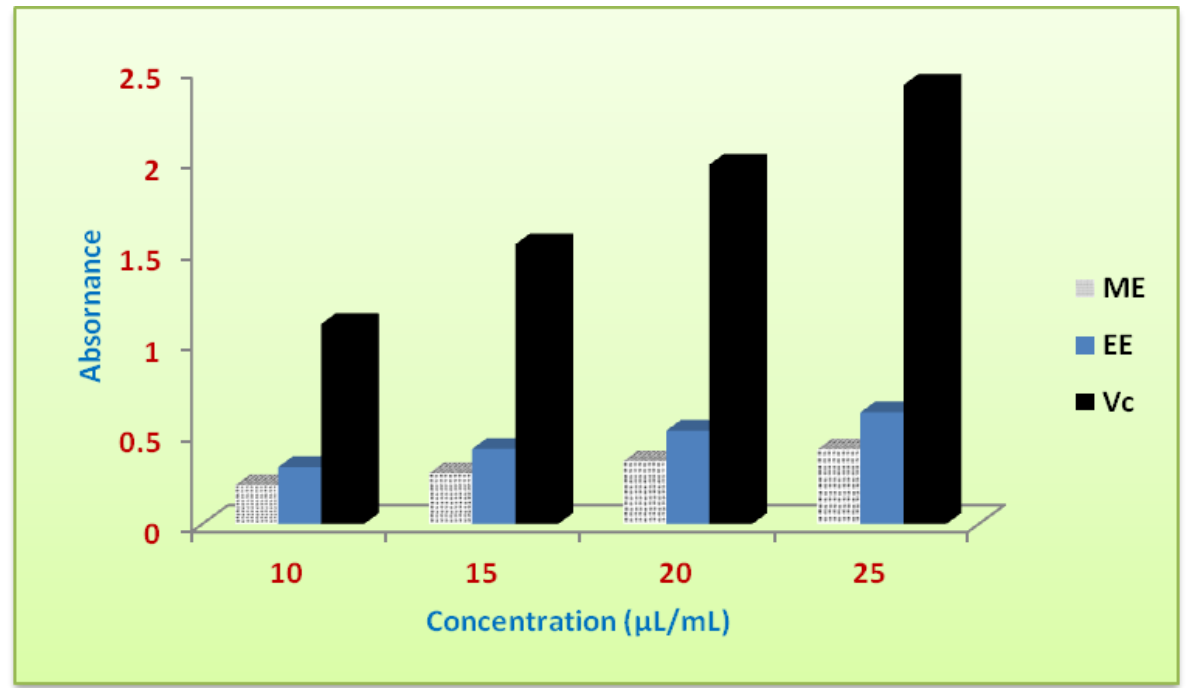

Fig. 7. Reducing power assay of different concentration of ME and EE extracts using ascorbic acid (Vc) as reference standard.

\section{REFFERENCES}

Ben-Hammouda, M.; R.J. Kremer; H.C. Minor and M. Sarwar (1995). A chemical basis for differential allelopathic potential of sorghum hybrids on wheat. J. Chemical Ecology, 21: 775 - 786.

Berger, S. and D. Sicker (2009). Classics in spectroscopy isolation and structure elucidation of natural products. Wiley-VCH., 195 - 196.

Bravo, I. (1998). Polyphenols: Chemistry, dietary sources, metabolism, and nutritional significance. Nutrition Reviews, 56: 317 - 333.

Chang, C.; M. Yang; H. Wen and J. Chern (2002). Estimation of total flavonoid content in propolis by two complementary colorimetric methods. J. Food Drug Analysis, 10: 178 -182.

Chaudhary, G.; S. Goyal and P. Poonia (2010). Lawsonia inermis Linnaeus: A Phytopharmacological Review. Int. J. Pharm. Sci. \& Drug Res., 2: 9198.

Dechatelet, L.R.; C.E. McCall; L.C. McPhial and R.B. Johnson (1974). Spectrophotometric method for determination of superoxide dismutase enzyme in serum. J. Clin. Invest., 53: 1197 - 1202.

Duan, Y.; R.A. Gross and S.S. Sheu (2007). $\mathrm{Ca}^{2+}$-dependent generation of mitochondrial reactive oxygen species serves as a signal for poly(ADPribose) polymerase-1 activation during glutamate excitotoxicity. J. Physiol., 585: $558-741$.

Ferreira, I.; P. Baptista; M. Vilas-Boas and L. Barros (2007). Free-radical scavenging capacity and reducing power of wild edible mushrooms from northeast Portugal: Individual cap and stipe activity. Food Chem., 100: 1511-1516. 
Gordon, M.F. (1990). The mechanism of antioxidant action in vitro. In: Hudson B.J.F.(ed), Food antioxidants London: Elsevier Applied Science, 1-18.

Hanna R.; J.N. Maciej; L. Lapinsky and L. Adamowicz (1998). Molecular structure and infra red spectra of 2-hydroxy-1,4-naphthaquinone; Experimental matrix isolation and theoretical Hatree-Fock and post Hatree-Fock study. Spec. Act., 54:1091-1103.

Harborne J.B. (1998). Phytochemical methods. A guide to modern techniques of plant analysis. (3rd edition). Chapman and Hall Co., New York, 1302.

Li, H.B.; K.W. Cheng; C.C. Wong; K.W. Fan; F. Chen and Y. Jiang (2007). Evaluation of antioxidant capacity and total phenolic content of different fractions of selected microalgae. Food Chem., 102: 771-776.

Martins, F.T.; A.C. Doriguetto; T.C. de Souza; K.R.D. de Souza; M.H. dos Santos; M.E.C. Moreira, and L.C.A. Barbosa (2008). Composition, and anti-inflammatory and antioxidant activities of the volatile oil from the fruit peel of Garcinia brasiliensis. Chem. Biodivers., 5: 251-258.

Nabavi, S.M.; M.A. Ebrahimzadeh; S.F. Nabavi; A. Hamidinia and A.R. Bekhradnia (2008). Determination of antioxidant activity, phenol and flavonoids content of Parrotia persica Mey. Pharmacologyonline, 2: 560-567.

Nagavani, V.; Y. Madhavi; D. Bhaskar Rao; P. Koteswara Rao and T. Raghava Rao (2010). Free radical scavenging activity and qualitative analysis of polyphenols by RP-HPLC in the flowers of Couroupita guianensis Abul. Electronic J. of Environmental, Agricultural and Food Chemistry, 9: 1471-1484.

Ou, B.; M. Hampsch-Woodill and R.L. Prior (2001). Development and validation of an improved oxygen radical absorbance capacity assay using fluorescein as the fluorescent probe. J. Nat. Prod., 63: 10351042.

Pham-Huy, L.A.; H. He and C. Pham-Huyc (2008). Free radicals, antioxidants in disease and health. Inter. J. of Biomed. Sci., 4: 89-96.

Sangameswaran, B.; B.R. Balakrishnan; C. Deshraj and B. Jayakar (2009). In vitro antioxidant activity of Thespesia Lampas Dalz and Gibs. Pakistan Journal of Pharmacy Science, 22: 368-372.

Terao, J. and M.K. Piskula (1997). Flavonoids as inhibitors of lipid peroxidation in membranes. In Rice- C.A. Evans and L. Packer (editor), Flavonoids in health and disease. Marcel Dekker. New York, 277-295.

Willcox, J.K.; S.L. Ash and G.L. Catignani (2004). Antioxidants and prevention of chronic disease. Critical Reviews in Food Science and Nutrition, 44: 275-295.

Winterbourn, C.C. and H.C. Sutton (1984). Hydroxyl radical production from hydrogen peroxide and enzymatically generated paraquat radicals: catalytic requirements and oxygen dependence. Arch. Biochem. Biophys., 235: 116-126. 
المواد الكيميائية النباتية والقدرة على مسك الثوارد الحرة لمستخلصسات من اوراق الحناء

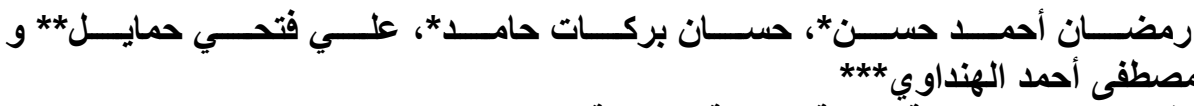

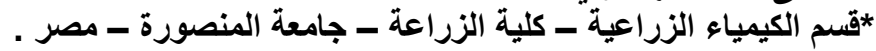

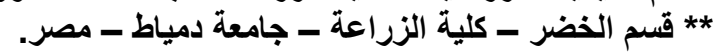
2** قسم الكيمياء الزراعية ـ كلية الزراعة. جامعة دمياطة دمياط ـ مصر.

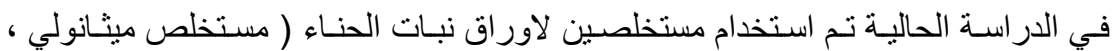

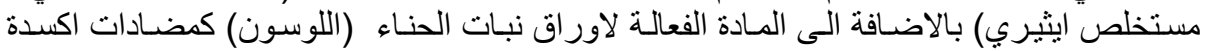

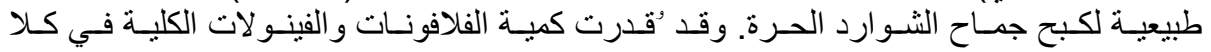

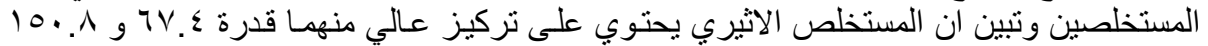

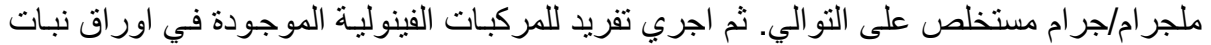

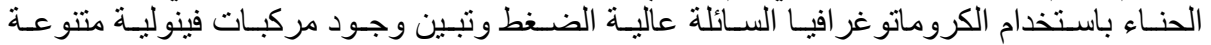

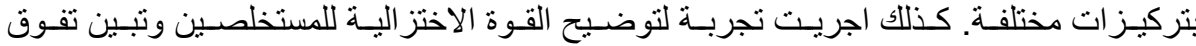

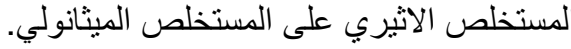

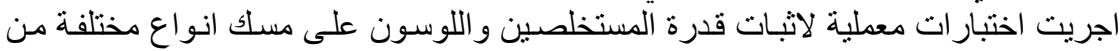

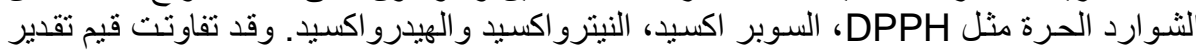

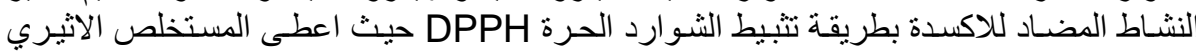

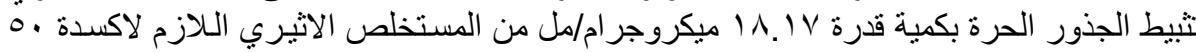

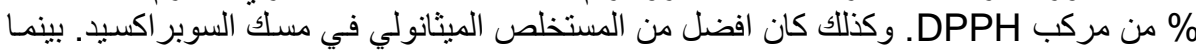

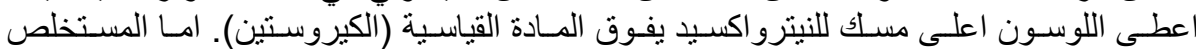
الميثانولي فله قدرة كبيرة على مسك الثوارد الحر الهيدروكسيدية.

كلية الزراعة - جامعة المنصورة كلية الزراعة - جامعة المنيا
قام بتحكيم البحث

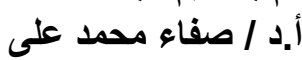

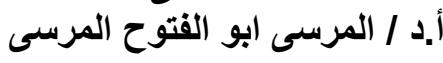

